Original Article - Clinical Science

\title{
Early worsening of diabetic retinopathy due to intensive glycaemic control
}

\author{
Shueh Wen Lim FRANZCO, ${ }^{1,2}$ Peter van Wijngaarden PhD FRANZCO, ${ }^{1,2,3}$ Colin A \\ Harper FRANZCO ${ }^{1,2}$ and Salmaan H Al-Qureshi FRANZCO ${ }^{1,2}$ \\ ${ }^{1}$ Royal Victorian Eye and Ear Hospital, ${ }^{2}$ Centre for Eye Research Australia, \\ ${ }^{3}$ Ophthalmology, Department of Surgery, University of Melbourne, Victoria, Australia
}

Correspondence: Dr Shueh Wen Lim, Royal Victorian Eye and Ear Hospital, 32 Gisborne Street, East Melbourne 3002, Australia

Email: shuehwen@gmail.com

Short running title: Early worsening of diabetic retinopathy

Received 11 April 2018; accepted 15 September 2018

Conflict of interest: None

Funding sources: PvW is the recipient of a University of Melbourne, Annemarie Mankiewicz-Zelkin Fellowship and a Sylvia and Charles Viertel Charitable Foundation Clinical Investigator Award (\#VLT2015C018). The Centre for Eye Research Australia receives Operational Infrastructure Support from the Victorian Government.

This is the author manuscript accepted for publication and has undergone full peer review but has not been through the copyediting, typesetting, pagination and proofreading process, which may lead to differences between this version and the Version of Record. Please cite this article as doi: 10.1111/ceo.13393

This article is protected by copyright. All rights reserved. 


\section{ABSTRACT}

The prevalence of diabetes and diabetic retinopathy is increasing around the world. Glycaemic control is important in reducing the long-term risk of complications of diabetes, however intensive glycaemic control, particularly in patients with longstanding and poorly controlled diabetes, is associated with the risk of early worsening of diabetic retinopathy and vision loss. We present two clinical cases to illustrate the presentation of early worsening and to highlight a role for intravitreal anti-vascular endothelial growth factor therapies in ameliorating this phenomenon, as well as a review of the current understanding of this phenomenon. We emphasise the importance of identifying individuals at risk of early worsening of diabetic retinopathy and recommend regular ophthalmological review during the period of intensive glycaemic control to ensure optimal visual outcomes.

Key words: diabetic retinopathy, early worsening phenomenon, glycaemic control, anti-vascular endothelial growth factor 


\section{INTRODUCTION}

Diabetes and diabetic retinopathy continue to rise in prevalence in Australia and around the world. ${ }^{1}$ In 1993, the Diabetes Control and Complications Trial (DCCT) demonstrated that intensive glycaemic control reduced the risk of microvascular complications in patients with type 1 diabetes mellitus (T1DM). ${ }^{2}$ The authors showed that intensive control of blood glucose levels delayed the onset of diabetic retinopathy (DR) with a $76 \%$ risk reduction compared to conventional therapy. In those with mild non-proliferative diabetic retinopathy (NPDR), intensive glycaemic control reduced the risk of DR progression by $54 \%$. This was supported by data from the United Kingdom Prospective Diabetes Study (UKPDS) which demonstrated that every percentage point reduction in haemoglobin $\mathrm{A} 1 \mathrm{c}(\mathrm{HbA1c})$ in individuals with type 2 diabetes (T2DM) was associated with a 35\% reduction in the relative risk of developing microvascular complications. ${ }^{3}$

However, despite the association between overall improvements in glycaemic control and reduced risk of development and progression of DR in the long term, the DCCT revealed a side effect in a small subset of patients. Consistent with results from previous trials, ${ }^{4-6}$ initial worsening of diabetic retinopathy occurred with intensive therapy. This 'early worsening' (EW) phenomenon has been reported in both $\mathrm{T} 1 \mathrm{DM}^{4,7,8}$ and T2DM ${ }^{9-11}$, and consisted mainly of increases in cotton wool spots and intraretinal microvascular abnormalities and/or diabetic macular oedema (DMO), indicating retinal ischaemia. In the DCCT, EW mainly affected the secondaryintervention cohort (ie those with T1DM for 1 to 15 years, very mild to moderate NPDR at baseline and urinary albumin excretion of $<200 \mathrm{mg} / 24 \mathrm{hr}$ ) during the first year of therapy, of which 22 percent in intensive therapy group experienced EW versus 13 percent in the conventional therapy group. The characteristic fundus abnormalities often disappeared by 18 months. ${ }^{2}$ 
Herein we report the clinical course of two patients, in whom rapid lowering of $\mathrm{HbA1C}$ resulted in deterioration of their diabetic retinopathy, and in whom use of anti-vascular endothelial growth factor (anti-VEGF) was associated with regression of this EW. We provide a review of the current understanding of this phenomenon.

\section{CASE 1:}

A 52-year-old male truck driver was referred by his general practitioner (GP) to the ophthalmology clinic for diabetic retinopathy screening. He was newly diagnosed with T2DM two months prior, with a HbA1c of $16.0 \%$. He was also found to have stage three diabetic nephropathy and peripheral neuropathy, and was commenced on oral hypoglycaemic agents and insulin. Fundus examination revealed severe NPDR without associated DMO. His best corrected visual acuity at the time was $6 / 9$ in both eyes. His other vascular risk factors included hypertension and hypercholesterolemia. He was advised to improve his glycaemic and blood pressure control and a review was scheduled in three months' time.

Five months later, he presented with a three-week history of deteriorating vision in both eyes. His best corrected visual acuity was reduced to 6/60 in his right eye and $6 / 120$ in his left eye. He reported rapid tightening of his glycaemic control, with a reduction of his $\mathrm{HbA} 1 \mathrm{c}$ from $16.0 \%$ to $6.9 \%$ in the preceding five months. Fundus examination revealed multiple cotton wool spots bilaterally, gross DMO and featureless peripheral fundi, without evidence of proliferative disease. Hypertension was excluded as a cause of retinopathy.

Optical coherence tomography (OCT) confirmed bilateral centre-involving DMO with subretinal fluid but without disorganisation of the inner retinal layers (Figure 1). The 
right and left thicknesses (CMT) were measured as $1155 \mu \mathrm{m}$ and $915 \mu \mathrm{m}$ respectively. Fluorescein angiography revealed bilateral macular ischaemia, with more extensive perifoveal capillary closure in the left eye than in the right eye (Figure 2). In view of the likely better prognosis of the right eye, the patient promptly received an intravitreal injection of bevacizumab $(1.25 \mathrm{mg} / 0.05 \mathrm{ml})$ in his right eye (on-label antiVEGF agents were not available at that time).

The patient demonstrated a marked response to the initial dose of bevacizumab his visual acuity improved from $6 / 60$ to $6 / 24$ and his CMT decreased from $1155 \mu \mathrm{m}$ to $321 \mu \mathrm{m}$ (Figure 1). The visual acuity in his untreated left eye remained at 6/120. He received a second intravitreal injection of bevacizumab in his right eye.

He continued to respond well to bevacizumab in his right eye, achieving a best corrected visual acuity of $6 / 12$ after 5 injections. Buoyed by this favourable outcome, a trial of monthly left intravitreal bevacizumab injections was commenced at this point. Significant improvement in his DMO, as indicated by a reduction in the CMT on OCT from $915 \mu \mathrm{m}$ to $486 \mu \mathrm{m}$, was not accompanied by an improvement in vision. He underwent panretinal photocoagulation to both eyes over three sessions, in addition to focal laser to microaneurysms in his right eye in an attempt to reduce the need for intravitreal anti-VEGF treatment. At the final review, following 6 bevacizumab injections in his right eye, his visual acuity was $6 / 18$ and $3 / 60$ in his right and left eyes, respectively. Unfortunately he did not attend further appointments and subsequently passed away from diabetic complications, hence his final visual outcome was unable to be determined.

\section{CASE 2:}


A 54 year old man was referred by his optometrist in February 2013 for a recent decrease in his visual acuity in the context of poorly controlled type 2 diabetes mellitus, hypertension and dyslipidaemia. At presentation, his HbA1c was $9.1 \%$. His blood pressure was within normal limits. His best corrected visual acuity was 6/9.5 in the right eye and 6/15 in the left eye. Clinical examination revealed bilateral severe non-proliferative diabetic retinopathy and DMO (Figure 3). OCT confirmed centreinvolving macular oedema, more marked in the right eye than in the left (CMT of $793 \mu \mathrm{m}$ and $785 \mu \mathrm{m}$ respectively) (Figure 4). Fluorescein angiography of the right eye showed moderate peripheral retinal capillary closure without significant macular capillary occlusion. There was confluent capillary closure in all four retinal quadrants in the left eye and significant perifoveal capillary closure indicative of macular ischaemia (Figure 5).

The patient was commenced on monthly intravitreal bevacizumab $(1.25 \mathrm{mg} / 0.05 \mathrm{ml})$ injections in both eyes to treat sight-threatening macular oedema (on-label antiVEGF agents were not available at that time). In addition, he underwent panretinal photocoagulation to his left eye over four sessions given the extent of the capillary closure. He opted for a low glycaemic index, high protein diet to control his blood sugar. Remarkably, his HbA1c reduced from $9.1 \%$ to $5.3 \%$ within three months, during which time he was receiving monthly bevacizumab injections to both eyes.

Three months after commencing monthly intravitreal bevacizumab therapy, his best corrected visual acuity was $6 / 6$ in his right eye, and 6/7.5 in his left eye. There was complete resolution of the DMO in both eyes (Figure 4). Apart from a minor increase in cotton wool spots (Figure 3), there was overall stabilisation of his diabetic retinopathy and his visual acuity was maintained at baseline levels. 
After three sessions of monthly bevacizumab, the frequency of injections was reduced to two-monthly. However, this resulted in worsening of his DMO (CMT increased from $277 \mu \mathrm{m}$ to $523 \mu \mathrm{m}$ in his right eye, and from $255 \mu \mathrm{m}$ to $369 \mu \mathrm{m}$ in his left eye) with an associated reduction in visual acuity to 6/12 in both eyes. He was advised to return to a monthly regimen of bevacizumab injections and panretinal photocoagulation to right eye. However, he was lost to follow-up and his long term visual outcome is unknown.

\section{DISCUSSION}

Case 1 serves to demonstrate the potential adverse impact of EW on vision, and emphasises that people with longstanding, poorly controlled T2DM and established retinopathy, may be at increased risk. A dramatic reduction in HbA1c occurred in both cases, with $1.8 \%$ per month in case 1 and $1.3 \%$ per month in case 2 and both benefited from intravitreal anti-VEGF therapy. Case 2 highlights a potential role for anti-VEGF therapy in ameliorating or preventing EW. Even though the fundus images of these two cases do not offer direct before and after image comparisons following tightening of blood sugar control, these images support the effect of anti-VEGF therapy in situations of intensive glycaemic control.

The risk of progression from severe NPDR or early proliferative DR (PDR) to high-risk severe PDR is approximately $25 \%$ over 4 to 6 months, and this risk may increase to $50 \%$ with intensive glycaemic control. ${ }^{12}$ Initial worsening in the DCCT occurred within 12 months, $^{7}$ consistent with other studies showing worsening within 3 to 12 months of the commencement of intensive insulin treatment. $5,6,8,10,13-20$

Despite having been described in the literature, the pathogenesis of EW is not well understood. It has been shown that frequency and severity of EW was associated 
with more advanced DR at baseline, higher $\mathrm{HbA1c}$ levels, and longer duration of diabetes. ${ }^{7,9,20}$ In addition, whilst the rapidity of blood glucose control and accompanying reduction in retinal blood flow have been implicated as important risk factors for $\mathrm{EW}^{5,6,21}$ others have proposed that the magnitude, but not the rapidity, of reduction of $\mathrm{HbA1C}$ during the first 6 months of intensive blood glucose control plays a more important role. ${ }^{7,9}$ The DCCT showed that every percentage point drop in $\mathrm{HbA1C}$ was associated with 1.6-fold increase in the risk of EW. This was also supported by studies showing that poor initial control paired with a dramatic reduction in $\mathrm{HbA1C}$ increases the risk of retinopathy progression significantly, ${ }^{15,22}$ with this having an even greater effect than prior duration of diabetes. ${ }^{22}$ The magnitude of $\mathrm{HbA1c}$ reduction is however closely related to the baseline $\mathrm{HbA1c}$, hence cannot be regarded as an independent factor.

Proposed mechanisms for this phenomenon include a decrease in availability of cellular energy substrates, a reduction in the ability of retinal circulation to autoregulate, and increase in growth factors. ${ }^{6,7,21,23}$ One prominent hypothesis is the upregulation of insulin-like growth factor 1 (IGF-1), a potent angiogenic and mitogenic hormone. ${ }^{24,25}$ Several studies showed that circulating IGF-1 levels are low in most people with type 1 diabetes. ${ }^{26,27}$ This is partly due to the lack of portal venous insulin in these people, as the secretion of IGF-1 by the liver varies according to insulin levels. Intensive glycaemic control results in upregulation of circulating IGF-1 with a brief overshoot, which may be due to insulin effects on IGF-binding proteins and IGF-1 bioavailability. ${ }^{28,29} \mathrm{An}$ increase in IGF-1 contributes to an increase in microvascular permeability and augmentation of the effects of angiogenic factors. ${ }^{25,30,31}$ IGF-1 has been demonstrated to induce the expression of vascular endothelial growth factor (VEGF), an angiogenic factor central to the pathogenesis of DR, and to enhance the downstream effects of VEGF. ${ }^{32,33}$ In experimental models, the intravitreal injection of IGF-1 results in microvascular abnormalities resembling 
those of DR, including increased basement membrane thickening, vasodilatation, vascular tortuosity, microaneurysms, intraretinal haemorrhage and neovascularisation. ${ }^{41,42}$

Increased serum IGF-1 levels have been correlated with rapidly accelerating DR and increased frequency of PDR, ${ }^{9,23,30,34}$ and 3-fold higher vitreous levels of IGF-1 have been found in people with PDR than in those without diabetes. ${ }^{35,36} \mathrm{~A}$ clinical trial of systemic IGF-1 administration to improve metabolic control in diabetes demonstrated progression of retinopathy and optic nerve neovascularisation. ${ }^{43,44}$ Chantelau et al. demonstrated that the cessation of insulin and intensive glycaemic control led to the stabilisation of retinopathy in individuals with T2DM and EW, and this was associated with reductions in serum IGF-1. ${ }^{24,37}$ Use of octreotide, a growth hormone and IGF-1 antagonist, has also been shown to delay or prevent disease progression in severe NPDR and early PDR. ${ }^{36,38-40}$ However, growth hormone and IGF-1 antagonists nor somatostatin analogues have not been studied specifically in the context of the EW phenomenon.

Recent work suggests that acute reductions in retinal glucose levels that accompany intensive glycaemic control may compound the effects of the hypoxia that is associated with capillary closure in DR. Hypoxic retinal injury may be reduced by hyperglycaemia as glucose is the major cellular energy source. Casson et al. demonstrated the glucose confers a neuroprotective effect in the setting of retinal hypoxia, through the glycolytic synthesis of adenosine triphosphate (ATP) and a reduction in the production of reactive oxygen species via glucose entry into the pentose phosphate pathway. ${ }^{50-52} \mathrm{~A}$ sudden dramatic tightening of glycaemic control may compromise this 'protective' effect, rendering retinal neurons vulnerable to injury. Nevertheless, while glucose may be protective to neurons in the context of 
retinal hypoxia, long-term hyperglycaemia is deleterious to both to retinal neurons and the microvasculature. ${ }^{53}$

Clinical reports of severe visual impairment associated with EW W $^{14,16-19,54}$ are balanced by those that describe transient and apparently reversible effects on vision. ${ }^{4-6,8,55}$ Moskalets et al. reported 6 of 122 patients with T1DM who had little or no retinopathy at baseline developed severe retinopathy, neovascularisation despite laser photocoagulation and vitreous haemorrhage within 1 year intensive glycaemic control. ${ }^{17}$ Mean HbA1c in these 6 patients reduced from $14.9 \%$ to $10.0 \%$ at 12 months, with initial rate of decline of $\mathrm{HbA} 1 \mathrm{c}$ level at approximately $1 \%$ per 47 days. ${ }^{17}$ In the DCCT, EW was associated with the development of high-risk PDR in 2 patients and clinically significant macular oedema in 3 , all of which responded well to treatment. ${ }^{7}$ Approximately $50 \%$ of people with EW at 3 months had recovered by 6 months, and more than $60 \%$ of those with any EW at 3 or 6 months had recovered by 12 months. EW occurred earlier and recovery was more frequent in those who received intensive therapy than in those who underwent to conventional therapy.

Bariatric surgical procedures can cause prompt and sustained normoglycaemia in up to $80 \%$ patients with $\mathrm{T} 2 \mathrm{DM}^{57,58}$ and episodes of post-operative reactive hypoglycaemia are not uncommon, making EW of DR a potential concern in this group. ${ }^{59}$ Retrospective studies have demonstrated variable effects of bariatric surgery on DR with worsening reported in between $1 \%$ and $45 \%$ of subjects 1 year after surgery. ${ }^{11,60-63}$ In a prospective observational study, $13 \%$ of patients exhibited progression of DR in the first 12 months post-operatively, but only $5 \%$ of those persisted at 12 months. ${ }^{64}$ The Surgical Therapy and Medications Potentially Eradicate Diabetes Efficiently (STAMPEDE) study compared the effects of intensive medical management with bariatric surgery on DR in T2DM. It was found that bariatric surgery did not significantly impact DR, and $86.5 \%$ of all patients had no change in 
their retinopathy 2 years post-operatively ${ }^{65}$ There is considerable variability in the literature reporting on the short-term impact of bariatric surgery on DR, likely due to differences in incidence of hypoglycaemia, which is not systematically tracked after surgery, or due to variations in the type of bariatric surgery performed. ${ }^{66}$ Whilst DR appears to remain relatively stable in most people after bariatric surgery, a preoperative retinal examination and careful monitoring of retinopathy post-operatively may be advisable, particularly in people with established retinopathy who undergo pronounced reductions in blood glucose levels. Similarly, studies have shown that pancreas or islet transplantation does not induce EW, but reduces the risk of DR progression instead. ${ }^{67-71}$

Despite the EW phenomenon, the long-term benefits of intensive glycaemic control are compelling and the occurrence of EW does not appear to compromise these. The DCCT showed that 'intensive' glycaemic control (mean HbA1c of $8.6 \%$ versus $12.8 \%$ in the conventional treatment group) was associated with a 2-fold increase in risk of EW, and the risk of sustained DR progression was 2-4 times higher in those that had EW than in those that did not develop EW. ${ }^{7}$ Importantly, people who received intensive therapy and developed EW still had a lower long-term risk of DR progression than did those who received conventional therapy and did not develop EW. $^{7}$

In addition, the Epidemiology of Diabetes Interventions and Complications (EDIC) study, a follow-up to DCCT study, demonstrated the phenomenon of "metabolic memory" 172 -- a phenomenon related to the sustained effects of prior glycaemic control on risk of vascular complications, irrespective of the level of glycaemic control later in the disease. People from both DCCT groups (intensive control group and conventional control group) went on to receive intensive therapy in the EDIC study, and mean HbA1c levels of $8.0 \%$ were achieved for both groups. The group 
with initial intensive therapy continued to have substantial reductions in the risks of DR progression (70\% reduction), PDR, macular oedema and requirement for laser treatment, compared with those who started with conventional therapy. ${ }^{2,72}$ This protective effect of early intensive control persisted even 10 years later, emphasising the long-term benefit of early intensive therapy despite the risk of EW. Altered expression of retinal glucose transporter 1 (GLUT1), as has been observed in the brain, may contribute to this effect. ${ }^{73}$

\section{RECOMMENDATIONS}

- The risk of EW has been demonstrated in those with dramatic reduction in $\mathrm{HbA1c}$ levels, hence identification of patients at high risk of EW, such as those with long history of poorly-controlled diabetes or previous advanced $D R$, is important.

- We recommend closer retinal follow-up before intensive therapy is initiated, as well as over the following 12 months.

- Retinal examinations at least every 3 months should be performed in those at high risk of EW.

- Particular attention should be paid to young patients with longstanding poorly controlled T1DM even in the absence of DR due to their high risk of rapidly progressive DR.

- There is no consistent evidence that controlling the speed of $\mathrm{HbA} 1 \mathrm{c}$ reduction will decrease the risk of EW, moreover, controlling the speed of decrease is difficult and unpredictable in clinical practice. This highlights the importance of close ophthalmological monitoring during this period of blood glucose control.

\section{CONCLUSIONS}


While the early worsening of DR may accompany rapid and marked blood glucose lowering, the existing evidence suggests that the long-term benefits of the early initiation of intensive glycaemic control outweigh this risk in most circumstances. As has been illustrated in the two cases described in this paper, the use of intravitreal anti-VEGF therapies may offer a useful approach to minimise or perhaps even prevent the morbidity associated with EW of DR. The influence of EW on inner retinal neuronal injury is not well understood at present and warrants further study. Forewarning of the potential for worsening of retinopathy should be given to people in whom the intensification of glycaemic control is considered, and regular ophthalmological review is advised in high risk individuals. A collaborative relationship between endocrinologists, general practitioners, bariatric surgeons and eye health professionals will ensure optimal outcomes for people at risk of EW. 


\section{REFERENCES}

1. Yau JW, Rogers SL, Kawasaki R, Lamoureux EL, Kowalski JW, Bek T, Chen SJ, Dekker JM, Fletcher A, Grauslund J, Haffner S, Hamman RF, Ikram MK, Kayama T, Klein BE, Klein R, Krishnaiah S, Mayurasakorn K, O'Hare JP, Orchard TJ, Porta M, Rema M, Roy MS, Sharma T, Shaw J, Taylor H, Tielsch JM, Varma R, Wang JJ, Wang N, West S, Xu L, Yasuda M, Zhang X, Mitchell P, Wong TY, Meta-Analysis for Eye Disease Study G. Global prevalence and major risk factors of diabetic retinopathy. Diabetes Care 2012; 35: 556-64.

2. The effect of intensive treatment of diabetes on the development and progression of long-term complications in insulin-dependent diabetes mellitus. The Diabetes Control and Complications Trial Research Group. The New England journal of medicine 1993; 329: 977-86.

3. Intensive blood-glucose control with sulphonylureas or insulin compared with conventional treatment and risk of complications in patients with type 2 diabetes (UKPDS 33). UK Prospective Diabetes Study (UKPDS) Group. Lancet 1998; 352: 837-53.

4. Blood glucose control and the evolution of diabetic retinopathy and albuminuria. A preliminary multicenter trial. The Kroc Collaborative Study Group. The New England journal of medicine 1984; 311: 365-72.

5. Lauritzen T, Frost-Larsen K, Larsen HW, Deckert T. Effect of 1 year of nearnormal blood glucose levels on retinopathy in insulin-dependent diabetics. Lancet 1983; 1: 200-4.

6. Dahl-Jorgensen K, Brinchmann-Hansen O, Hanssen KF, Sandvik L, Aagenaes O. Rapid tightening of blood glucose control leads to transient deterioration of retinopathy in insulin dependent diabetes mellitus: the Oslo study. $\mathrm{Br}$ Med J (Clin Res Ed) 1985; 290: 811-5. 
7. Early worsening of diabetic retinopathy in the Diabetes Control and Complications Trial. Arch Ophthalmol 1998; 116: 874-86.

8. Lauritzen T, Frost-Larsen $\mathrm{K}$, Larsen HW, Deckert T. Two-year experience with continuous subcutaneous insulin infusion in relation to retinopathy and neuropathy. Diabetes 1985; 34 Suppl 3: 74-9.

9. Henricsson M, Berntorp K, Berntorp E, Fernlund P, Sundkvist G. Progression of retinopathy after improved metabolic control in type 2 diabetic patients. Relation to IGF-1 and hemostatic variables. Diabetes Care 1999; 22: 1944-9.

10. Roysarkar TK, Gupta A, Dash RJ, Dogra MR. Effect of insulin therapy on progression of retinopathy in noninsulin-dependent diabetes mellitus. American journal of ophthalmology 1993; 115: 569-74.

11. Varadhan L, Humphreys T, Hariman C, Walker AB, Varughese GI. GLP-1 agonist treatment: implications for diabetic retinopathy screening. Diabetes Res Clin Pract 2011; 94: e68-71.

12. Davis MD. Diabetic retinopathy. A clinical overview. Diabetes Care 1992; 15: 1844-74.

13. Agardh CD, Eckert B, Agardh E. Irreversible progression of severe retinopathy in young type I insulin-dependent diabetes mellitus patients after improved metabolic control. J Diabetes Complications 1992; 6: 96-100.

14. Dandona P, Bolger JP, Boag F, Fonesca V, Abrams JD. Rapid development and progression of proliferative retinopathy after strict diabetic control. $\mathrm{Br}$ Med J (Clin Res Ed) 1985; 290: 895-6.

15. Funatsu $H$, Yamashita $H$, Ohashi $Y$, Ishigaki T. Effect of rapid glycemic control on progression of diabetic retinopathy. Jpn J Ophthalmol 1992; 36: 356-67.

16. Lawrence JR, Bedford GJ, Thomson R. Rapid development during puberty of proliferative retinopathy after strict diabetic control. Lancet 1985; 2: 332. 
17. Moskalets E, Galstyan G, Starostina E, Antsiferov M, Chantelau E. Association of blindness to intensification of glycemic control in insulin-dependent diabetes mellitus. J Diabetes Complications 1994; 8: 45-50.

18. Puklin JE, Tamborlane WV, Felig P, Genel M, Sherwin RS. Influence of longterm insulin infusion pump treatment of type I diabetes on diabetic retinopathy. Ophthalmology 1982; 89: 735-47.

19. van Ballegooie E, Hooymans JM, Timmerman Z, Reitsma WD, Sluiter WJ, Schweitzer NM, Doorenbos H. Rapid deterioration of diabetic retinopathy during treatment with continuous subcutaneous insulin infusion. Diabetes Care 1984; 7: 236-42.

20. Henricsson M, Nilsson A, Janzon L, Groop L. The effect of glycaemic control and the introduction of insulin therapy on retinopathy in non-insulindependent diabetes mellitus. Diabet Med 1997; 14: 123-31.

21. Grunwald JE, Riva CE, Martin DB, Quint AR, Epstein PA. Effect of an insulininduced decrease in blood glucose on the human diabetic retinal circulation. Ophthalmology 1987; 94: 1614-20.

22. Shurter A, Genter P, Ouyang D, Ipp E. Euglycemic progression: worsening of diabetic retinopathy in poorly controlled type 2 diabetes in minorities. Diabetes Res Clin Pract 2013; 100: 362-7.

23. Merimee TJ, Zapf J, Froesch ER. Insulin-like growth factors. Studies in diabetics with and without retinopathy. The New England journal of medicine 1983; 309: 527-30.

24. Chantelau E, Meyer-Schwickerath R, Klabe K. Downregulation of serum IGF-1 for treatment of early worsening of diabetic retinopathy: a long-term followup of two cases. Ophthalmologica 2010; 224: 243-6.

25. Attia N, Caprio S, Jones TW, Heptulla R, Holcombe J, Silver D, Sherwin RS, Tamborlane WV. Changes in free insulin-like growth factor- 1 and leptin 
concentrations during acute metabolic decompensation in insulin withdrawn patients with type 1 diabetes. J Clin Endocrinol Metab 1999; 84: 2324-8.

26. Amiel SA, Sherwin RS, Hintz RL, Gertner JM, Press CM, Tamborlane WV. Effect of diabetes and its control on insulin-like growth factors in the young subject with type I diabetes. Diabetes 1984; 33: 1175-9.

27. Tan K, Baxter RC. Serum insulin-like growth factor I levels in adult diabetic patients: the effect of age. J Clin Endocrinol Metab 1986; 63: 651-5.

28. Chantelau E, Kohner EM. Why some cases of retinopathy worsen when diabetic control improves. BMJ (Clinical research ed) 1997; 315: 1105-6.

29. Hanaire-Broutin H, Sallerin-Caute B, Poncet MF, Tauber M, Bastide R, Rosenfeld R, Tauber JP. Insulin therapy and GH-IGF-I axis disorders in diabetes: impact of glycaemic control and hepatic insulinization. Diabetes \& metabolism 1996; 22: 245-50.

30. Lauszus FF, Klebe JG, Bek T, Flyvbjerg A. Increased serum IGF-I during pregnancy is associated with progression of diabetic retinopathy. Diabetes 2003; 52: 852-6.

31. Frystyk J. The growth hormone hypothesis - 2005 revision. Horm Metab Res 2005; 37 Suppl 1: 44-8.

32. Fukuda R, Hirota K, Fan F, Jung YD, Ellis LM, Semenza GL. Insulin-like growth factor 1 induces hypoxia-inducible factor 1-mediated vascular endothelial growth factor expression, which is dependent on MAP kinase and phosphatidylinositol 3-kinase signaling in colon cancer cells. The Journal of biological chemistry 2002; 277: 38205-11.

33. Hellstrom A, Engstrom E, Hard AL, Albertsson-Wikland K, Carlsson B, Niklasson A, Lofqvist C, Svensson E, Holm S, Ewald U, Holmstrom G, Smith LE. Postnatal serum insulin-like growth factor I deficiency is associated with retinopathy of prematurity and other complications of premature birth. Pediatrics 2003; 112: 1016-20. 
34. Dills DG, Moss SE, Klein R, Klein BE. Association of elevated IGF-I levels with increased retinopathy in late-onset diabetes. Diabetes 1991; 40: 1725-30.

35. Meyer-Schwickerath R, Pfeiffer A, Blum WF, Freyberger H, Klein M, Losche C, Rollmann R, Schatz H. Vitreous levels of the insulin-like growth factors I and II, and the insulin-like growth factor binding proteins 2 and 3, increase in neovascular eye disease. Studies in nondiabetic and diabetic subjects. $J$ Clin Invest 1993; 92: 2620-5.

36. Grant M, Russell B, Fitzgerald C, Merimee TJ. Insulin-like growth factors in vitreous. Studies in control and diabetic subjects with neovascularization. Diabetes 1986; 35: 416-20.

37. Chantelau E, Meyer-Schwickerath R. Reversion of 'early worsening' of diabetic retinopathy by deliberate restoration of poor metabolic control. Ophthalmologica 2003; 217: 373-7.

38. Grant MB, Mames RN, Fitzgerald C, Hazariwala KM, Cooper-DeHoff R, Caballero S, Estes KS. The efficacy of octreotide in the therapy of severe nonproliferative and early proliferative diabetic retinopathy: a randomized controlled study. Diabetes Care 2000; 23: 504-9.

39. McCombe M, Lightman S, Eckland DJ, Hamilton AM, Lightman SL. Effect of a long-acting somatostatin analogue (BIM23014) on proliferative diabetic retinopathy: a pilot study. Eye (Lond) 1991; 5 ( Pt 5): 569-75.

40. Mallet B, Vialettes B, Haroche S, Escoffier P, Gastaut P, Taubert JP, Vague P. Stabilization of severe proliferative diabetic retinopathy by long-term treatment with SMS 201-995. Diabete Metab 1992; 18: 438-44.

41. Grant MB, Mames RN, Fitzgerald C, Ellis EA, Caballero S, Chegini N, Guy J. Insulin-like growth factor I as an angiogenic agent. In vivo and in vitro studies. Ann N Y Acad Sci 1993; 692: 230-42.

42. Danis RP, Bingaman DP. Insulin-like growth factor-1 retinal microangiopathy in the pig eye. Ophthalmology 1997; 104: 1661-9. 
43. Kolaczynski JW, Caro JF. Insulin-like growth factor I therapy for diabetes mellitus? Diabetes Care 1994; 17: 92-6.

44. Langford KS, Miell JP. The insulin-like growth factor-I/binding protein axis: physiology, pathophysiology and therapeutic manipulation. Eur J Clin Invest 1993; 23: 503-16.

45. Cho YH, Craig ME, Donaghue KC. Puberty as an accelerator for diabetes complications. Pediatr Diabetes 2014; 15: 18-26.

46. Pituitary destruction for diabetic retinopathy. Lancet 1969; 2: 415-6.

47. Merimee TJ. Diabetic retinopathy. A synthesis of perspectives. The New England journal of medicine 1990; 322: 978-83.

48. Sonksen PH, Russell-Jones D, Jones RH. Growth hormone and diabetes mellitus. A review of sixty-three years of medical research and a glimpse into the future? Horm Res 1993; 40: 68-79.

49. Lundbaek K, Christensen NJ, Jensen VA, Johansen K, Olsen TS, Hansen AP, Orskov $\mathrm{H}$, Osterby R. Diabetes, diabetic angiopathy, and growth hormone. Lancet 1970; 2: 131-3.

50. Casson RJ, Chidlow G, Wood JP, Osborne NN. The effect of hyperglycemia on experimental retinal ischemia. Arch Ophthalmo/ 2004; 122: 361-6.

51. Casson RJ, Wood JP, Osborne NN. Hypoglycaemia exacerbates ischaemic retinal injury in rats. Br J Ophthalmo/ 2004; 88: 816-20.

52. Han G, Wood JP, Chidlow G, Mammone T, Casson RJ. Mechanisms of neuroprotection by glucose in rat retinal cell cultures subjected to respiratory inhibition. Investigative ophthalmology \& visual science 2013; 54: 7567-77.

53. de Moraes $\mathrm{G}$, Layton $\mathrm{CJ}$. Therapeutic targeting of diabetic retinal neuropathy as a strategy in preventing diabetic retinopathy. Clinical \& experimental ophthalmology 2016; 44: 838-52. 
54. Daneman D, Drash AL, Lobes LA, Becker DJ, Baker LM, Travis LB. Progressive retinopathy with improved control in diabetic dwarfism (Mauriac's syndrome). Diabetes Care 1981; 4: 360-5.

55. Diabetic retinopathy after two years of intensified insulin treatment. Follow-up of the Kroc Collaborative Study. The Kroc Collaborative Study Group. Jama 1988; 260: 37-41.

56. Marso SP, Daniels GH, Brown-Frandsen K, Kristensen P, Mann JF, Nauck MA, Nissen SE, Pocock S, Poulter NR, Ravn LS, Steinberg WM, Stockner M, Zinman B, Bergenstal RM, Buse JB. Liraglutide and Cardiovascular Outcomes in Type 2 Diabetes. The New England journal of medicine 2016; 375: 311-22.

57. Buchwald H, Estok R, Fahrbach K, Banel D, Jensen MD, Pories WJ, Bantle JP, Sledge I. Weight and type 2 diabetes after bariatric surgery: systematic review and meta-analysis. Am J Med 2009; 122: 248-56.e5.

58. Mingrone $G$, Panunzi S, De Gaetano A, Guidone C, Iaconelli A, Leccesi L, Nanni G, Pomp A, Castagneto M, Ghirlanda G, Rubino F. Bariatric surgery versus conventional medical therapy for type 2 diabetes. The New England journal of medicine 2012; 366: 1577-85.

59. Cohen R, Pechy F, Petry T, Correa JL, Caravatto PP, Tzanno-Martins C. Bariatric and metabolic surgery and microvascular complications of type 2 diabetes mellitus. J Bras Nefro/ 2015; 37: 399-409.

60. Miras AD, Chuah LL, Lascaratos G, Faruq S, Mohite AA, Shah PR, Gill M, Jackson SN, Johnston DG, Olbers T, le Roux CW. Bariatric surgery does not exacerbate and may be beneficial for the microvascular complications of type 2 diabetes. Diabetes Care 2012; 35: e81.

61. Murphy R, Jiang Y, Booth M, Babor R, MacCormick A, Hammodat H, Beban G, Barnes RM, Vincent AL. Progression of diabetic retinopathy after bariatric surgery. Diabet Med 2015; 32: 1212-20. 
62. Thomas RL, Prior SL, Barry JD, Luzio SD, Eyre N, Caplin S, Stephens JW, Owens DR. Does bariatric surgery adversely impact on diabetic retinopathy in persons with morbid obesity and type 2 diabetes? A pilot study. $J$ Diabetes Complications 2014; 28: 191-5.

63. Kim YJ, Seo du R, Kim MJ, Lee SJ, Hur KY, Choi KS. CLINICAL COURSE OF DIABETIC RETINOPATHY IN KOREAN TYPE 2 DIABETES AFTER BARIATRIC SURGERY: A Pilot Study. Retina 2015; 35: 935-43.

64. Brynskov T, Laugesen CS, Svenningsen AL, Floyd AK, Sorensen TL. Monitoring of Diabetic Retinopathy in relation to Bariatric Surgery: a Prospective Observational Study. Obes Surg 2016; 26: 1279-86.

65. Singh RP, Gans R, Kashyap SR, Bedi R, Wolski K, Brethauer SA, Nissen SE, Bhatt $D L$, Schauer P. Effect of bariatric surgery versus intensive medical management on diabetic ophthalmic outcomes. Diabetes Care 2015; 38: e323.

66. Gorman DM, le Roux CW, Docherty NG. The Effect of Bariatric Surgery on Diabetic Retinopathy: Good, Bad, or Both? Diabetes Metab J 2016; 40: 35464.

67. Virk SA, Donaghue KC, Wong TY, Craig ME. Interventions for Diabetic Retinopathy in Type 1 Diabetes: Systematic Review and Meta-Analysis. American journal of ophthalmology 2015; 160: 1055-64.e4.

68. Ramsay RC, Goetz FC, Sutherland DE, Mauer SM, Robison LL, Cantrill HL, Knobloch WH, Najarian JS. Progression of diabetic retinopathy after pancreas transplantation for insulin-dependent diabetes mellitus. The New England journal of medicine 1988; 318: 208-14.

69. Chow VC, Pai RP, Chapman JR, O'Connell PJ, Allen RD, Mitchell P, Nankivell $B J$. Diabetic retinopathy after combined kidney-pancreas transplantation. Clinical transplantation 1999; 13: 356-62. 
70. Giannarelli R, Coppelli A, Sartini MS, Del Chiaro M, Vistoli F, Rizzo G, Barsotti M, Del Prato S, Mosca F, Boggi U, Marchetti P. Pancreas transplant alone has beneficial effects on retinopathy in type 1 diabetic patients. Diabetologia 2006; 49: 2977-82.

71. Thompson DM, Meloche M, Ao Z, Paty B, Keown P, Shapiro RJ, Ho S, Worsley D, Fung M, Meneilly G, Begg I, Al Mehthel M, Kondi J, Harris C, Fensom B, Kozak SE, Tong SO, Trinh M, Warnock GL. Reduced progression of diabetic microvascular complications with islet cell transplantation compared with intensive medical therapy. Transplantation 2011; 91: 373-8.

72. Aiello LP. Diabetic retinopathy and other ocular findings in the diabetes control and complications trial/epidemiology of diabetes interventions and complications study. Diabetes Care 2014; 37: 17-23.

73. Kumagai AK, Kang YS, Boado RJ, Pardridge WM. Upregulation of blood-brain barrier GLUT1 glucose transporter protein and mRNA in experimental chronic hypoglycemia. Diabetes 1995; 44: 1399-404. 
Figure 3. Initial fundus photographs and at three months

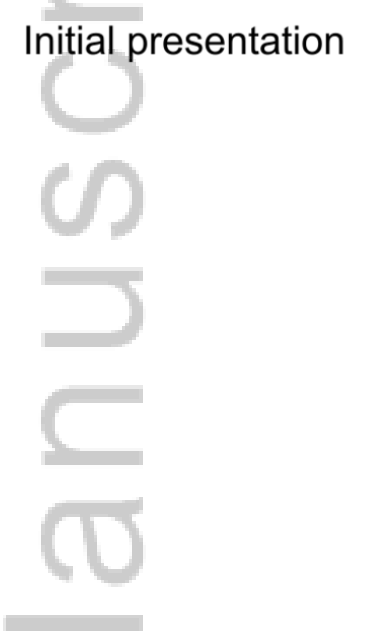

Three months after monthly

bevacizumab injections along with a dramatic reduction in $\mathrm{HbA} 1 \mathrm{c}$

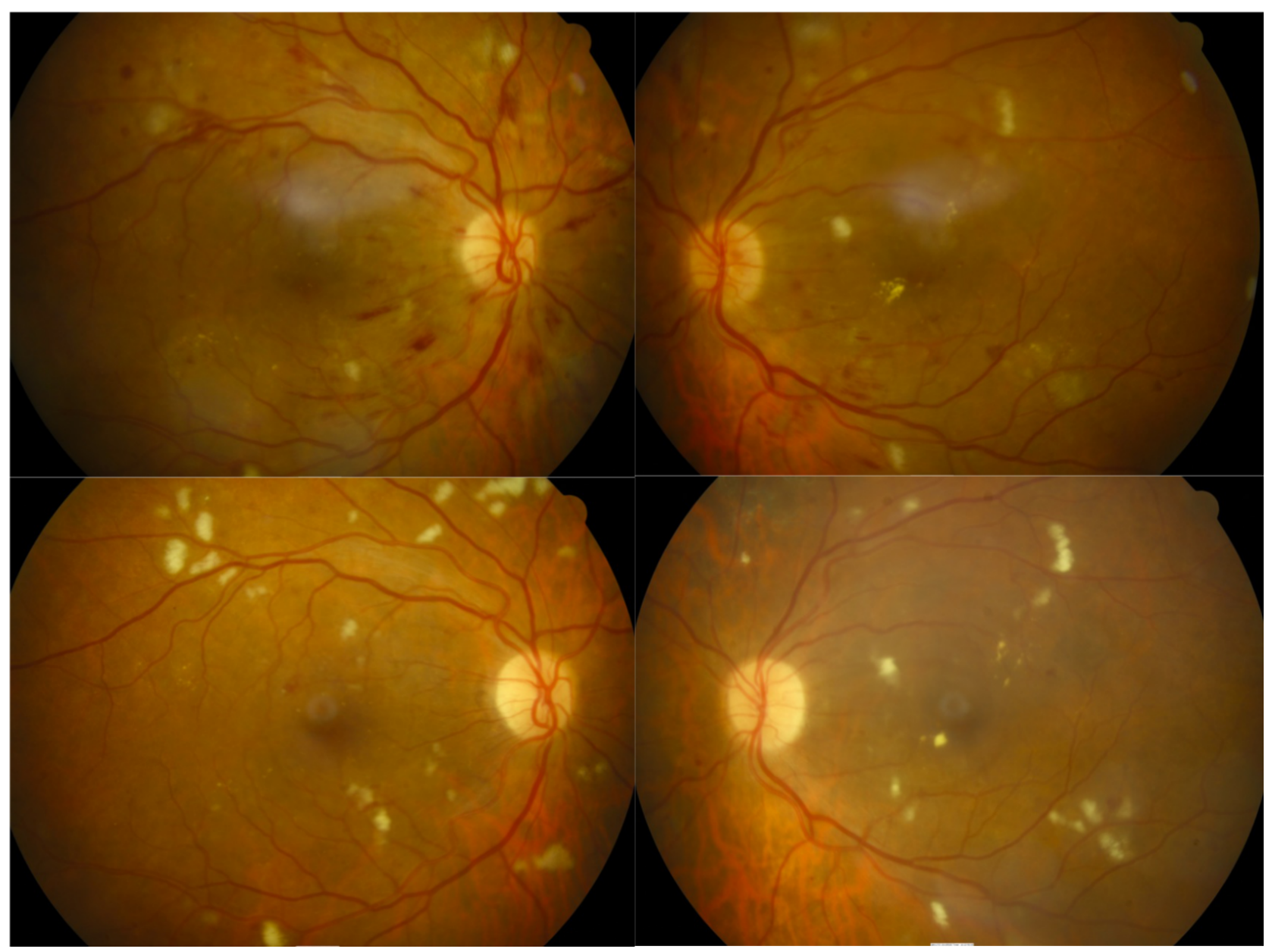

Figure3.png

This article is protected by copyright. All rights reserved. 
Figure 4. OCT macula demonstrating good response to intravitreal bevacizumab injections

Right eye

Left eye

Initial presentation

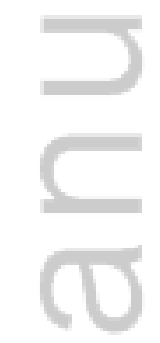

Three months after monthly bevacizumab injections
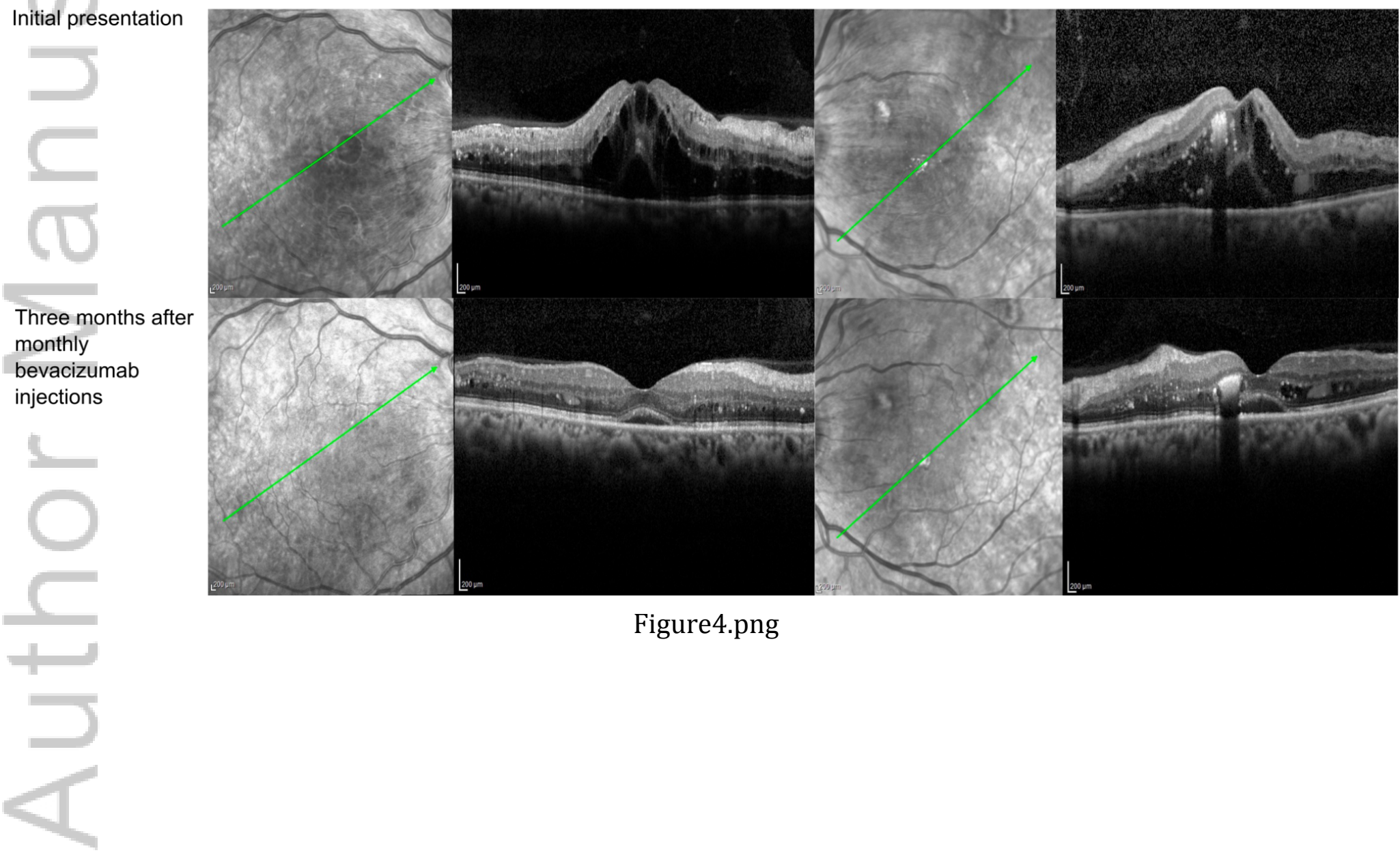

Figure4.png

This article is protected by copyright. All rights reserved. 
